\title{
Prediction and Influence Factors Analysis of Forest Fire Risk Degree-—A Case Study of Daxing'anling Area
}

\author{
Li Jing*, Yu Qian, Cui Tiejun \\ College of Geographic and Environmental Sciences, Tianjin Normal University, Tianjin, China
}

\section{Email address:}

lijing_09@yeah.net (Li Jing), 15122559722@163.com (Yu Qian), tiejun_cui@163.com (Cui Tiejun)

${ }^{*}$ Corresponding author

\section{To cite this article:}

Li Jing, Yu Qian, Cui Tiejun. Prediction of Forest Fire Risk Degree and Its Influence Factors Analysis_—A Case Study of Daxing'anling Area. Science Discovery. Vol. 5, No. 6, 2017, pp. 450-456. doi: 10.11648/j.sd.20170506.20

Received: September 30, 2017; Accepted: October 8, 2017; Published: November 21, 2017

\begin{abstract}
Analyze the risk of forest fire and its influencing factors is of great significance, which can provide scientific basis for forecasting and controlling forest fires, so as to reduce economic losses and casualties. Based on vegetation index data and meteorological data from May 13 to 22, 2017, the forest risk rating was calculated using the evaluation criteria of forest fire hazard in Daxing'anling Area, and then the influencing factors of fire were analyzed. The results show that the reason for the spring fire in Daxing'anling Area is that the spring temperature is gradually increasing, but the precipitation does not increase synchronously, and thus resulting in low air humidity and dryness. Moreover, in spring and summer alternating date, there are usually strong atmospheric activity and high wind speed, which lead the forest fire risk increasing. In this weather conditions, the forest area can easily lead to fire, and the spread of the fire is also difficult to control. However, vegetation coverage increase could reduce the risk of fire. According to this algorithm, it is possible to predict the fire risk level in the forest area so as to determine the high probability of fire occurrence area, which could provides a reference for planning fire prevention measures and reasonable flight routes of UAVs for forest administrator.
\end{abstract}

Keywords: Daxing'anling, Vegetation Coverage, Meteorological Factor, Forest Fire Risk Forecast

\section{森林地区火险等级预报及影响因素分析一一以大兴安岭为例}

李静*, 于茜, 崔铁军

地理与环境科学学院, 天津师范大学, 天津, 中国

邮箱

lijing_09@yeah.net (李静),15122559722@163.com（于茜）, tiejun_cui@163.com（崔铁军）

摘要：对森林火灾发生风险及其影响因素的分析, 能够为预测和防治森林火灾提供科学依据, 从而减少经济损失和人员伤 亡, 具有重要意义。本文以大兴安岭为研究区，利用2017年5月13日-5月22日植被指数数据与气象数据，基于森林火险天 气等级评定标准, 计算火险等级, 分析火灾发生的影响因素。结果表明, 大兴安岭春季火灾发生的主要原因是, 春季温度 逐渐升高, 但是降水量并没有同步增加, 造成空气的湿度低、干燥, 使得春季火险等级偏高。此外, 春夏季节交替时期, 大气活动强烈, 风速较大, 空气的流动使火灾发生的危险性升高。在该天气状态下, 森林地区极易引起火灾, 并且火势的 蔓延也较难控制。随着植被覆盖度的增加, 火灾发生风险会有所降低。根据这一算法可以预测森林地区的火险等级, 确定 火灾发生概率高的区域，有助于森林管理员的防火措施工作以及能够为无人机规划合理的飞行路线提供参考。

关键词：大兴安岭，植被覆盖度，气象因素，森林火险等级预报 


\section{1. 引言}

森林火灾的发生对森林的储量和温室气体的排放有 重要影响, 此外, 林火的发生也会导致森林资源减少、生 态环境破坏和人类生命财产的损失，因此对森林火灾进行 积极有效的预防和控制一直以来都是十分重要的研究课 题[1-2]。预测火险区划等级是一项重要的防火技术措施, 能够为林火预防、林火扑救以及森林管理员因地制宜的进 行防火规划和部署工作提供了科学有效的依据[3]。研究划 分森林火险等级的方法可以分为数理统计方法、经验模型、 火险工具等。根据研究范围则可以分为森林火险气象等级 模型、森林火险可燃物含水率模型、森林火险多因子综合 模型等[4]。本文主要针对森林火险气象等级模型进行研究。 随着卫星遥感技术的飞速发展所带来的变革, 其在森林火 灾领域的应用也逐渐引起了国内外研究学者的关注 [5]。我 国专家也在森林防火预测方面做了研究, 1957年王正非研 究了东北林区火线区划[6]，1993年郑焕能、姚树人等研究 了中国森林火险区划[7]。国内外学者基于气象资料和火灾 频发资料，利用不同模型在不同时空尺度上进行了森林火 险区划研究 [8 16]。已有研究为我国森林火险分布提供了 整体的认识, 但是, 森林火险等级随时间有很大变化, 受 到局地温度、湿度、覆盖度含水量、风速等因素的影响, 因此, 实时的计算森林地区的火险等级对提前做好防火措 施有重要意义。1992年3月23日我国颁布了“LY1063-92《全 国森林火险区划等级》行业标准”。本研究根据这一标准, 以大兴安岭为研究区, 利用大兴安岭区域2017年植被指数
产品与日最高气温、日最小相对湿度、最大风速、降水量 等气象数据的影响因子, 基于森林火险等级模型, 预测大 兴安岭的火险等级。利用遥感和地理信息系统去分析火灾 问题, 有助于森林管理员建立森立火灾预防措施和减灾策 略, 使得研究区域内的火灾影响因子得到有效的管理。

\section{2. 研究地区与研究方法}

\section{1. 研究区概况}

大兴安岭位于黑龙江省、内蒙古自治区东北部, 地处 $116^{\circ} 49^{\prime}-126^{\circ} 38^{\prime} \mathrm{E}, 47^{\circ} 1^{\prime}-53^{\circ} 28^{\prime} \mathrm{N}$ 之间, 是中国纬度最高的 边境地区, 冬长夏短, 属寒温带大陆性季风气候, 具有明 显的山地气候特征, 并且四季变化明显。大兴安岭原始森 林茂密, 是中国重要的林业基地之一, 也是我国面积最为 集中的重点国有林区、重要的原始林区和重点火险区 [17-18]。因地理位置及海拔高度的不同, 呈现不同的森林 植被类型, 具有代表性的有杜鹃落叶松林、越桔落叶松林、 杜香落叶松林、草类落叶松林和白桦落叶松林等。由于大 面积地区被针叶林植被覆盖, 油松类物种又极易发生火灾, 可能会带来严重的危害, 因此大兴安岭是每年春、秋季节 火灾预防工作的重点区域。

本文中我们主要从日最高气温、日最小相对湿度、最 大风速、降水量等气象数据和植被覆盖度等几方面的影响 因素进行分析讨论。

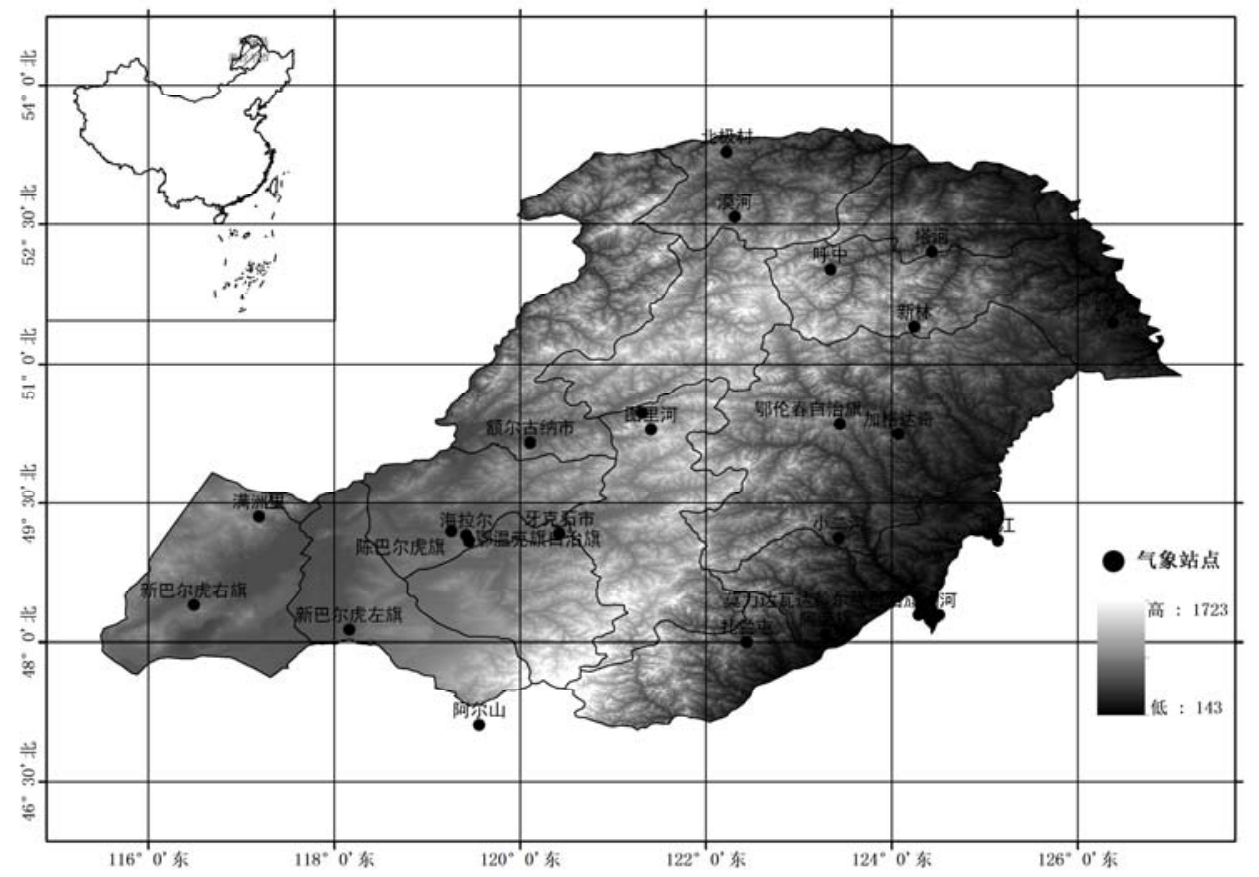

图1 研究区站点位置。

\section{2. 研究数据和方法}

本文选取中国气象数据网提供的大兴安岭地区 25 个 气象站点（见图1）2017年5月份13日-5月22日的日最高温
度、日最小相对湿度、最大风速及降水量等影响因子的逐 时气象数据。在遥感及地理信息系统的基础上, 本文使用 USGS网站上面提供的2016年全年和2017年5月的16天合 
成的 $250 \mathrm{~m}$ 分辨率植被指数数据产品(MOD13Q1)计算植被 覆盖度。

首先, 将逐时气象数据换算成逐日数据, 再对其进行 Kriging空间插值运算。其次, 利用MRT软件对获取的植 被指数数据进行拼接、几何纠正和投影变换处理。最后, 计算植被覆盖度。覆盖度的算法如下:

$$
\mathrm{F}=\left(\mathrm{NDVI}-\mathrm{NDVI}_{\min }\right) /\left(\mathrm{NDVI}_{\max }-\mathrm{NDVI}_{\min }\right)
$$

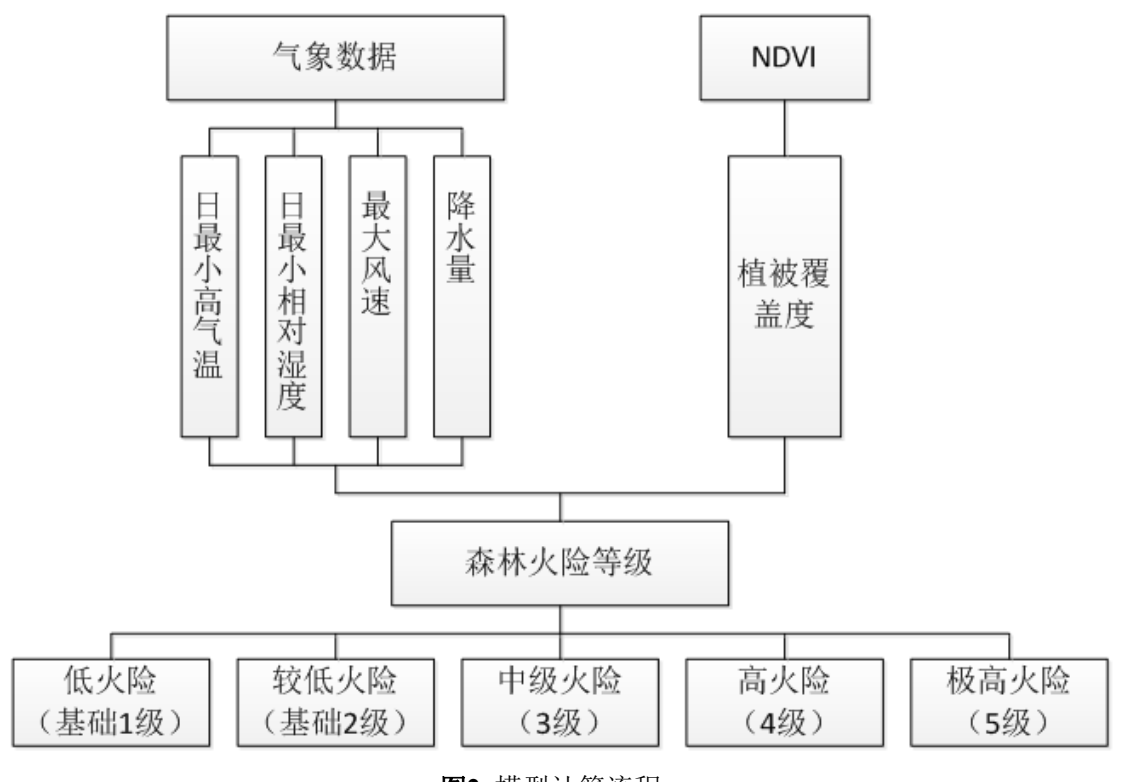

图2 模型计算流程。

\section{3. 结果与分析}

\section{1. 火险等级空间分布}

根据逐日的日最高气温、日最小相对湿度、最大风速、 降水量数据和植被覆盖度数据, 计算出大兴安岭地区 2017 年5月21日和22日的火险等级空间分布。图3中, 色调由绿 色到红色代表火险等级逐渐升高, 土黄色代表四级高火险,
公式(1)中, $\mathrm{NDVI}_{\min }$ 代表区域内裸土或无植被覆盖区

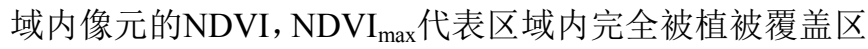
域内像元的NDVI。

依据《中华人民共和国林业行业标准一全国森林火险 天气等级》中的森林火险天气指数计算模型, 预测区域火 险等级。此标准模型规定了全国森林火险天气等级及其使 用方法, 适用于全国各类林区的森林防火期当日的森林火 险天气等级实况的评定。 (a)

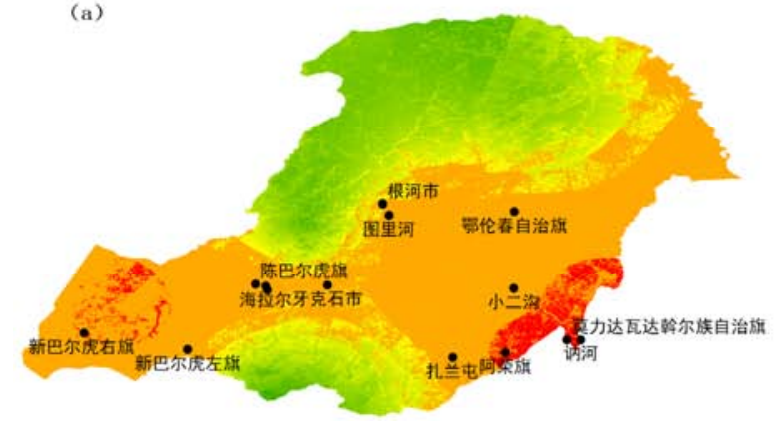

(b)

红色代表五级极高火险。结果表明, 在大兴安岭内的 $48^{\circ} \mathrm{N}$ 到 $50^{\circ} \mathrm{N}$ 之间, 火险等级偏高, 由西向东分别经过新巴尔虎 右旗、海拉尔、加格达奇, 火险等级达到四级和五级。其 它区域大部分是三级及以下火险等级。从时间上来看, 22 日的火险等级明显高于 21 日, 主要分布在新巴尔虎右旗和 加格达奇附近。

图3 大兴安岭 2017 年5月21日(a)和22日(b)的火险等级分布。

\section{2. 火灾影响因子的分布}

气象因素和地表覆盖度是判断火灾发生概率的重要 因素, 通过分析气象因素和地表覆盖的空间分布, 揭示影 响火险等级的主要因素。

\subsection{1. 气象因素的分布}

基于大兴安岭 25 个气象站点上 21 日和 22 日的日最高 气温、日最小相对湿度、最大风速、降水量数据, 对日最 高气温、日最小相对湿度和最大风速进行空间插值计算。 
对降水量前八日累积量对应的火险等级数值进行空间插 值计算(图4)。结果显示，春季气温逐渐较高，达到15度到 25 度，但是降水量以及相对湿度偏低，均在 $22 \%$ 以下。由 此可见, 温度升高, 但是空气比较干燥、湿度偏低, 是引 起春季火险等级偏高的重要因素。春夏季节交替时期，大
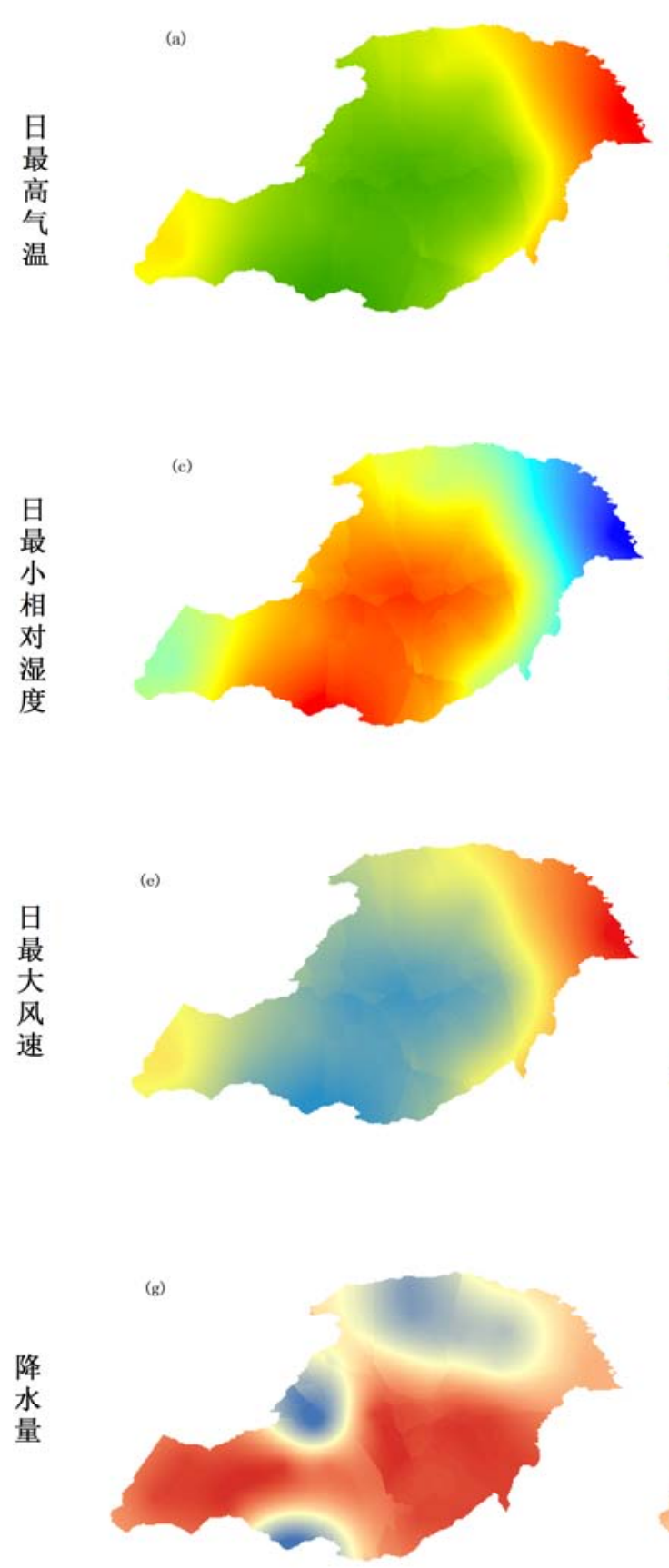
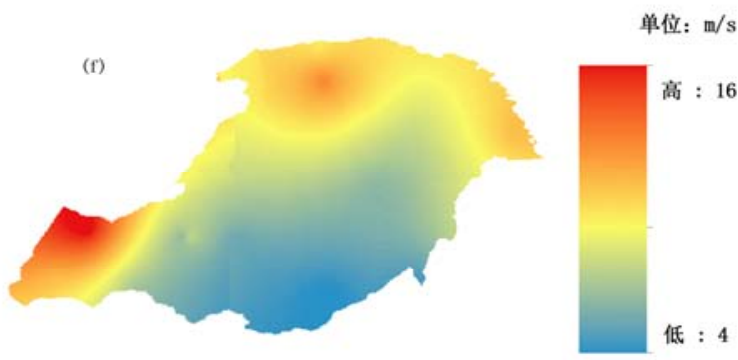

气活动强烈, 风速较大, 空气的流动使火灾发生的危险性 升高。在该天气状态下，一旦有火灾诱发因素，极易造成 火灾, 并且火势的蔓延也会很难控制。图中的降水量因素 是前 8 天内的累积降水, 大兴安岭北部地区的降水降低了 该区域的火险发生风险。
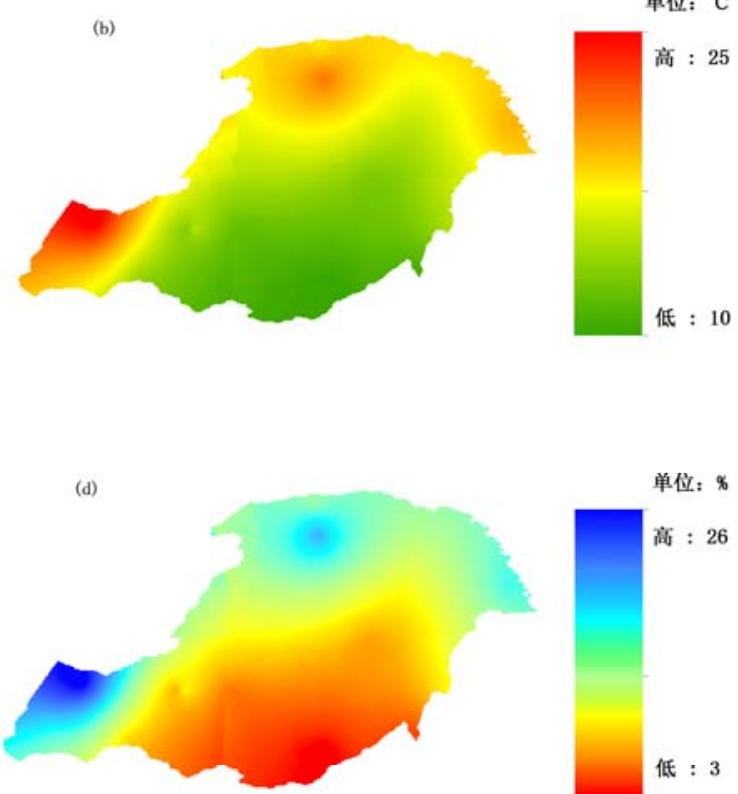

(h)

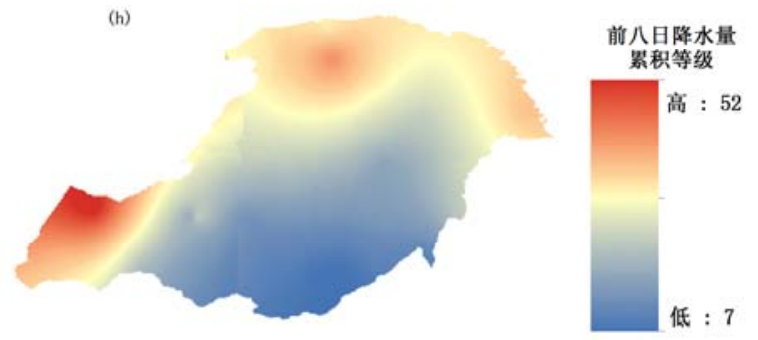

图4 大兴安岭2017年5月21日 (a, c, e, g) 和22日(b, d, f, h) 的日最高气温、日最小相对湿度、最大风速和降水量的空间分布。

\subsection{2. 地表覆盖度的分布}

本文使用 MOD13Q1 产品级的 NDVI (Normalized Difference Vegetation Index, 归一化植被指数)数据, 计算大 兴安岭植被覆盖度。图5中，色调由紫色到绿色代表植被 覆盖度由少到多。结果显示, 大兴安岭北部以及其东南麓 的植被覆盖度较好。地表覆盖类型中，干枯的植被、或者
油脂含量较高的植被类型会增加火险等级, 雪盖或者新生 长的阔叶植被会降低火险等级。早春季节, 温度较低, 地 表可能的雪盖会大大降低火险发生的概率; 春季中后期, 温度升高, 植被的覆盖度较低, 此时是火险等级较高的季 节; 进入夏季, 虽然温度继续升高, 但是由于地表覆盖度 的增加以及降水量的增加, 火险等级会降低。 


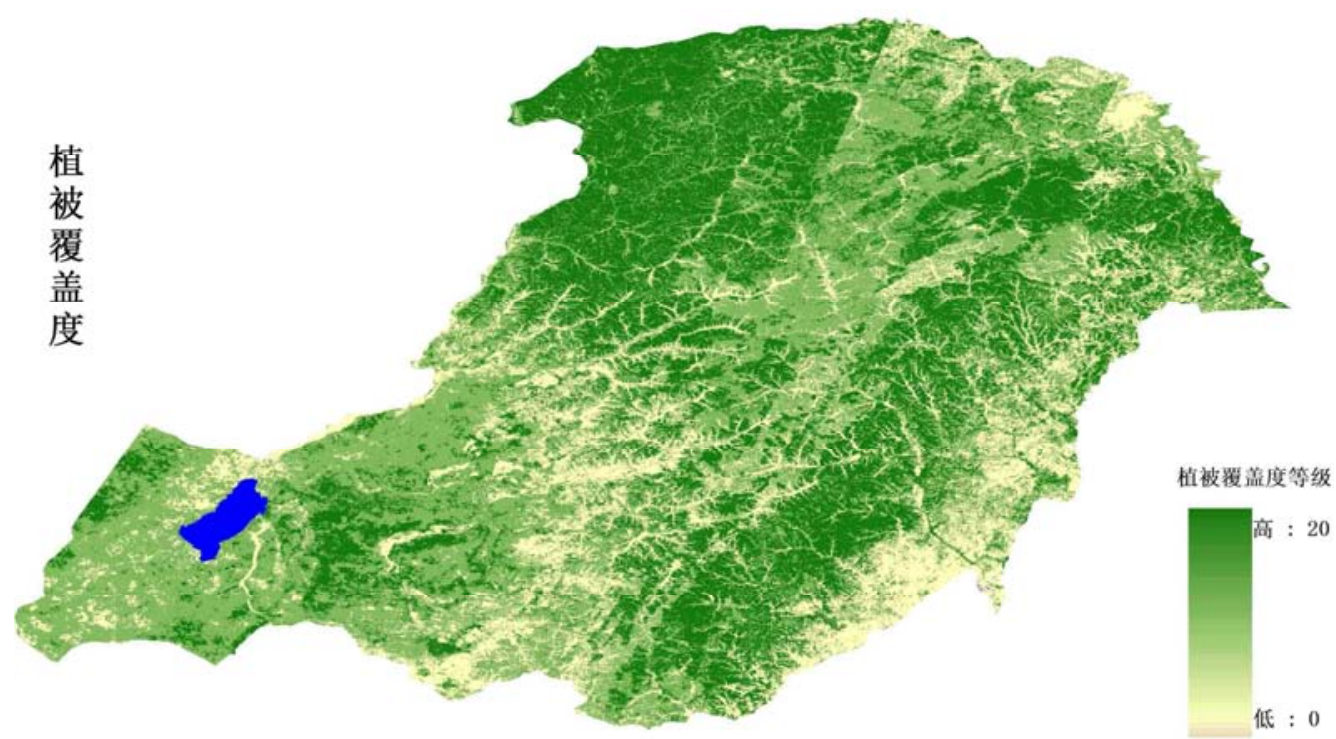

图5 植被覆盖度。

\section{3. 前期气象因素的变化曲线}

分别统计大兴安岭地区2017年5月21日和22日的位于 火险等级四级以及以上等级的站点的日最高气温、日最小 相对湿度、最大风速和降水量的前期变化曲线。如图3所 示, 21 日和 22 日火险等级是四级及以上站点分别有 14 个站 点和19个站点。图5中, 左边一列代表21日火险等级四级 及以上站点的气象因素的统计, 右边一列代表22日火险等 级四级及以上站点的气象因素的统计。结果显示, 21 日和 22日在火险等级超过四级的站点分布区, 日最高气温在 5 月 17 和 18 日均超过了 $30^{\circ} \mathrm{C}$, 日最小湿度持续下降至低于
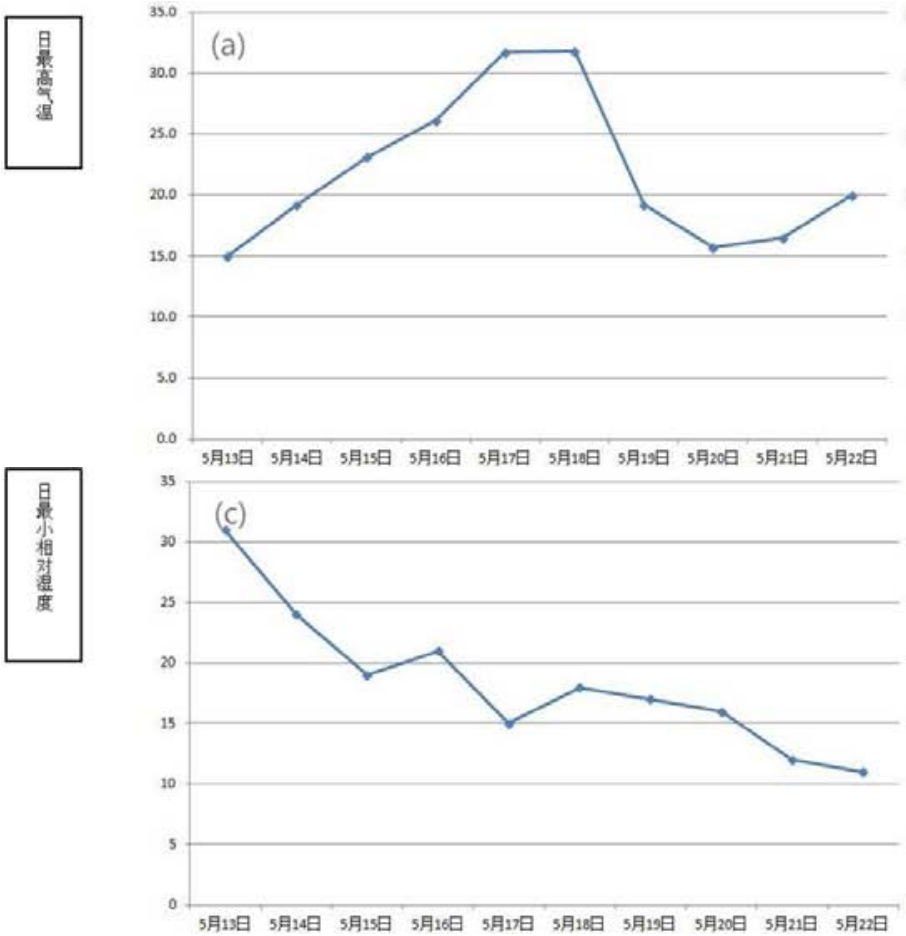

$15 \%$ 以下。在 14 个站点的分布区域内, 降水量较低, 至 5 月 15 日后连续 7 天没有降水; 在 19 个站点的分布区域内, 5.17 日有 $12 \mathrm{~mm}$ 的降水, 对北部地区的干旱起到了一定的 缓解作用。并且, 该期间的风速较大, 范围是4-11米/秒, 不仅增加了火灾发生的风险，也增加了火灾发生后，控制 蔓延速度的难度。由图3可知，与21日相比，22日的火险 等级有明显的上升现象。从气象因素来看, 从 21 日到 22 日, 气温上升了 $4^{\circ} \mathrm{C}$ 左右, 空气湿度降低, 持续无降水, 并且风速增加了 2 米/秒，均导致了火线等级的增加。
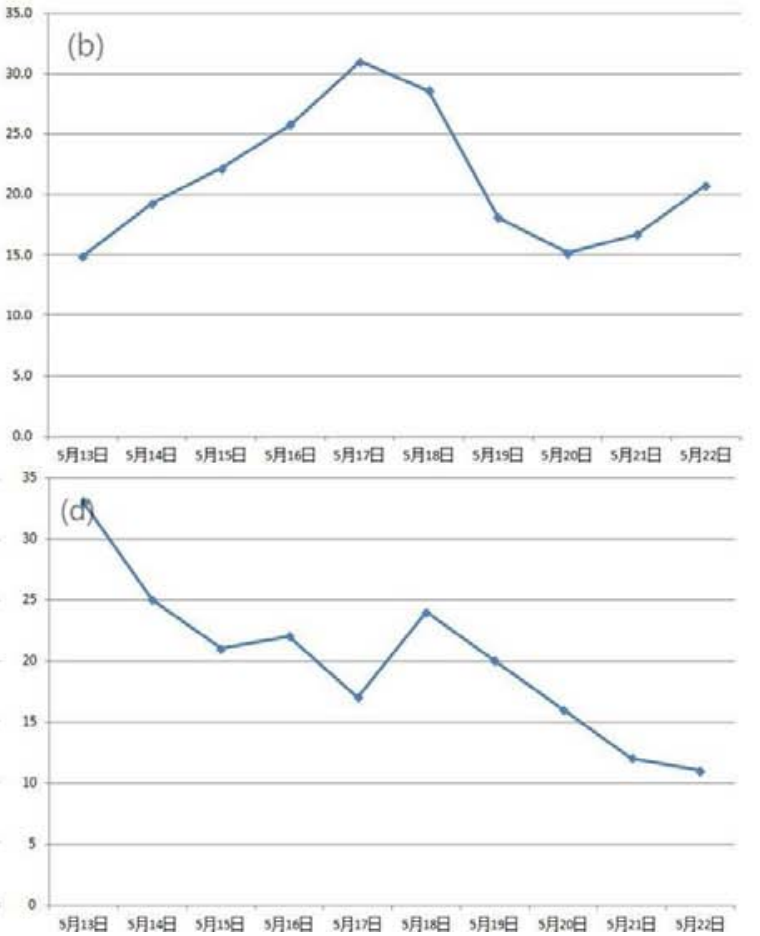

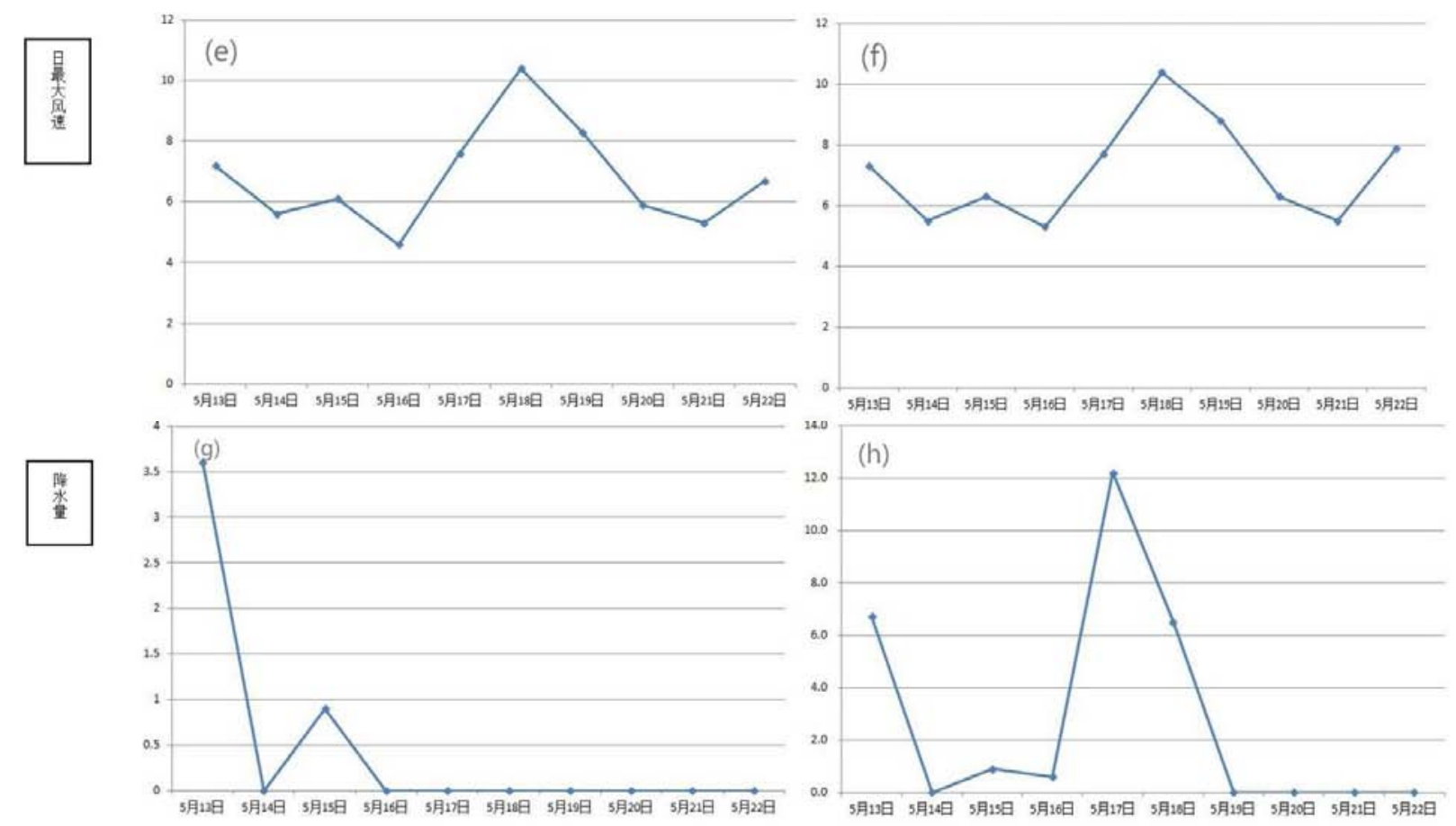

图6 大兴安岭 21 日 $(a, c, e, g)$ 和 22 日 $(b, d, f, h)$ 四级及以上火险站点的日最高气温、日最小相对湿度、最大风速和降水量的统计。

\section{4. 结论及展望}

温度的升高、水分的滞后到达以及地表覆盖类型是引 起火险等级升高的重要因素。影响火灾发生的气象因素之 间，存在一定的相互作用，例如，温度的升高会降低空气 中的湿度, 降水量的增加则会增加空气中的湿度, 因此, 其中具有更加复杂的机制和机理需要进一步研究。此外, 火灾的发生是火险等级和火灾的诱发因素均满足一定条 件的后果, 因此, 做好防火措施, 是减少火灾的重要手段。

需要说明的是, 由于气象数据可得性的限制, 本文使 用距大兴安岭 4.29 日火灾间隔20天，后续研究中尽量使用 火灾前的气象数据, 使用更精细的火灾模型进行研究。

\section{致谢}

本文为成果转化项目《森林火险等级预报系统的构建 和应用》(047/ZX0471601119)的阶段性成果之一。

\section{参考文献}

[1] 郭福涛, 苏漳文, 马祥庆, 宋禹辉, 孙龙, 胡海清, 杨婷 婷. 大兴安岭塔河地区雷击火发生驱动因子综合分析 $[\mathrm{J}]$. 生 态学报, 2015,35(19):6439-6448。

[2] 赵璠, 舒立福, 杨征夺, 张明远. 西南林区森林火灾火险 预报模型评价研究 $[\mathrm{J}]$. 林业机械与木工设备, 2017。

[3] Qu Y(屈宇), Li B-H(李保会). 2001. Present situation of re-search on forest fire danger grade classification. Hebei J
For Or-chard Res(河北林果研究), 16(4):392 396(in Chinese).

[4] 张伟, 郑显. 关于大兴安岭地区森林火灾与气象因素的模 型及分析 $[J]$. 东北林业大学学报, 2015。

[5] 李晓恋. 基于MODIS数据的多因子协同作用下森林入灾预 测监测研究 $[J]$. 中国科学技术大学, 2016。

[6] 王正非. 东北林区森林火灾基本情况调查研究报告[M]. 北 京: 北京科学出版社, 1957。

[7] 郑焕能森林防火, 哈尔滨东北林业大学出版社, 1994:22。

[8] Amparo AB, Oscar FR. 2003. An intelligent system for forest firerisk prediction and fire fighting management in Galicia. Exp Syst Appl, 25(6):545 554.

[9] Fu Z-Q(傅泽强), Dai E-F(戴尔阜). 2001. Seasonal dynamic char-acteristics and climate condition analysis of forestry fire risk in Da-xing'an Mountains. J Nat Dis(自然灾害学报), 10(4):113 116(in Chinese).

[10] Gao C-H(高昌海), Yan Y-T(颜元庭), Gu X-F(顾香凤), et al. 1994. Forest fire risk zone mapping of Shibazhan Bureau. For Sci Technol(林业科技), 19(2):33 34(in Chinese).

[11] Grishin AM, Filkov AI. 2003. A model of prediction of forest-fire hazard. J Eng Phys Thermoph, 76(5):321 325.

[12] Guo P(郭平), Sun G(孙刚), Zhou D-W(周道玮), et al. 2001. Study on fire behavior in grassland. Chin J Appl Ecol(应用生 态学报), 12(5):746 748(in Chinese).

[13] Huang H-K(黄厚康), Lin J-S(林继生), Xiong Y-H(熊燕辉). 1995. An evaluation model for forest-fire risk in Guangdong Province. J Trop Meteorol(热带气象学报), 11(1):66 72(in Chinese). 
[14] Jiang S-L(蒋少林), Yang J-Y(杨剑英), Fan J-S(范金绶), et al. 1995. A study of forest fire danger rating in Leshan city. Sichuan For Sci Technol(四川林业科技), 16(3):12 17(in Chinese).

[15] Li F-Q(李富强), Li Y-Y(李荣荣), Wang Y-L(王艳玲), et al. 1997. Study on forest-fire risk zone in Jilin Province. Jilin For Sci Technol(吉林林业科技), (5):20～25(in Chinese).

[16] Liu H-B(刘海波), Yuan J(袁靖), Yang R-K(杨汝康). 1995. Astudy on the climatic indices and zonal division of the forest-fire danger in Heilongjiang Province. J Northeast Agric Univ(东北农业大学学报), 26(1):145 150(in Chinese).

[17] 张道斌. 扑火指挥员手册 $[\mathrm{G}]$. 牙克石: 大兴安岭林管局森 林防火指挥部, 2000。

[18] ZHANG D B. Forest fire suppression commander's handbook [G]. Yakeshi: The Forest Fire Prevention Headquarters of Daxing' anling Forestry Administration Bureau, 2000. 